\title{
Ethanol Extract of Cudrania tricuspidata Leaf Ameliorates Hyperuricemia in Mice via Inhibition of Hepatic and Serum Xanthine Oxidase Activity
}

\author{
Seung-Hui Song, ${ }^{1}$ Dae-Hun Park $\left(\mathbb{D},{ }^{2}\right.$ Min-Suk Bae, ${ }^{3}$ Chul-Yung Choi, ${ }^{4}$ Jung-Hyun Shim, \\ Goo Yoon, ${ }^{1}$ Young-Chang Cho, ${ }^{5}$ Deuk-Sil Oh, ${ }^{6}$ In-Soo Yoon $\mathbb{D}^{7},{ }^{7}$ and Seung-Sik Cho $\mathbb{D}^{1}$ \\ ${ }^{1}$ Department of Pharmacy, College of Pharmacy, Mokpo National University, Muan, Jeonnam 58554, Republic of Korea \\ ${ }^{2}$ Department of Nursing, Dongshin University, Naju, Jeonnam 58245, Republic of Korea \\ ${ }^{3}$ Department of Environmental Engineering, Mokpo National University, Muan, Jeonnam 58554, Republic of Korea \\ ${ }^{4}$ Department of Natural Medicine Research, Jeonnam Institute of Natural Resources Research, Jangheung, \\ Jeonnam 59338, Republic of Korea \\ ${ }^{5}$ College of Pharmacy, Chonnam National University, Buk-gu, Gwangju 61186, Republic of Korea \\ ${ }^{6}$ Jeonnam Forest Resource Research Institute, Naju, Jeonnam 58213, Republic of Korea \\ ${ }^{7}$ Department of Manufacturing Pharmacy, College of Pharmacy, Pusan National University, Geumjeong, \\ Busan 46241, Republic of Korea
}

Correspondence should be addressed to In-Soo Yoon; insoo.yoon@pusan.ac.kr and Seung-Sik Cho; sscho@mokpo.ac.kr

Received 5 September 2018; Accepted 8 November 2018; Published 2 December 2018

Academic Editor: Attila Hunyadi

Copyright (C) 2018 Seung-Hui Song et al. This is an open access article distributed under the Creative Commons Attribution License, which permits unrestricted use, distribution, and reproduction in any medium, provided the original work is properly cited.

\begin{abstract}
Cudrania tricuspidata Bureau (Moraceae) (CT) is a dietary and medicinal plant distributed widely in Northeast Asia. There have been no studies on the effect of CT and/or its active constituents on in vivo xanthine oxidase (XO) activity, hyperuricemia, and gout. The aim of this study was to investigate XO inhibitory and antihyperuricemic effects of the ethanol extract of CT leaf (CTLE) and its active constituents in vitro and in vivo. Gas chromatography-mass spectrometry (GC-MS) and high-performance liquid chromatography (HPLC) analyses were used to determine a chemical profile of CTLE. XO inhibitory and antihyperuricemic effects of CTLE given orally (30 and $100 \mathrm{mg} / \mathrm{kg}$ per day for 1 week) were examined in potassium oxonate-induced hyperuricemic ICR mice. CTLE exhibited XO inhibitory activity in vitro with an $\mathrm{IC}_{50}$ of $368.2 \mu \mathrm{g} / \mathrm{mL}$, significantly reduced serum uric acid levels by approximately 2 -fold (7.9 nM in normal mice; $3.8 \mathrm{nM}$ in $30 \mathrm{mg} / \mathrm{kg}$ CTLE; $3.9 \mathrm{nM}$ in $100 \mathrm{mg} / \mathrm{kg}$ CTLE), and significantly alleviated hyperuricemia by reducing hepatic (by 39.1 and $41.8 \%$ in 30 and $100 \mathrm{mg} / \mathrm{kg}$, respectively) and serum XO activity (by 30.7 and $50.1 \%$ in 30 and $100 \mathrm{mg} / \mathrm{kg}$, respectively) in hyperuricemic mice. Moreover, several XO inhibitory and/or antihyperuricemic phytochemicals, such as stigmasterol, $\beta$-sitosterol, vitamin E, rutin, and kaempferol, were identified from CTLE. Compared with rutin, kaempferol showed markedly higher XO inhibitory activity in vitro. Our present results demonstrate that CTLE may offer a promising alternative to allopurinol for the treatment of hyperuricemia and gout.
\end{abstract}

\section{Introduction}

Hyperuricemia is defined as abnormally high levels of uric acid in the blood stream. In a chronic hyperuricemic state, uric acid can be crystallized and deposited as monosodium urate in the joints. This can cause inflammatory arthritis with severe pain, which is defined as gout [1]. Thus, hyperuricemia has been regarded as the main etiological factor in gout and the first phases in the process of gout [2]. Worldwide, the prevalence of gout is reported to be approximately $0.1 \%-10 \%$, although it is increasing in both developed and developing countries [3]: more than two million people in the United States are reportedly afflicted with gout [4] and the prevalence of gout and hyperuricemia in China was $1.1 \%$ and $13.3 \%$, respectively [5]. Moreover, patients with gout or hyperuricemia have a much higher risk for the development 
of various comorbidities, such as hypertension, metabolic syndromes, and cardiovascular diseases [6-9].

As xanthine oxidase $(\mathrm{XO})$ is a key enzyme involved in the purine nucleotide catabolism from hypoxanthine to uric acid, both uric acid and XO have been regarded as the main biochemical index and relevant therapeutic target for hyperuricemia and gout [10]. Thus, the management of hyperuricemia and gout is primarily aimed at the modulation of the activity of XO. Allopurinol is a representative $\mathrm{XO}$ inhibitor, used primarily for the treatment of hyperuricemia and gout. However, allopurinol induces hypersensitivity reactions with a probability of up to $2 \%$, some of which can be severe, with a mortality of up to $20 \%$ [11]. Moreover, other adverse reactions associated with allopurinol include fetal liver necrosis, eosinophilia, Stevens-Johnson syndrome, and nephropathy [12]. Owing to these unmet medical needs, the development of alternative herbal medicines for the treatment of hyperuricemia and gout is an active field of study [13].

Cudrania tricuspidata Bureau (Moraceae) (CT) is a dietary and medicinal plant which is distributed widely in Northeast Asia (South Korea, Japan, and China) [14]. The Donguibogam, an essential bible of Asian traditional medicine, reported that the daily intake of CT stem or leaf extracts at doses of 50-70 g can ameliorate inflammation and pain. Several previous studies reported that the root, fruit, and/or leaf of CT possessed various pharmacological activities, such as anti-inflammatory, cytotoxic, antiobesity, and hepatoprotective activity [15-19]. We previously prepared an ethanolic extract of CT leaf and optimized its extraction conditions with respect to various biological activities [15]. In the previous study, the optimized CT leaf extract (CTLE) was found to possess in vitro XO inhibitory activity [15]. However, to the best of our knowledge, there have been no studies on the effect of $\mathrm{CT}$ and/or its active constituents on in vivo $\mathrm{XO}$ activity, hyperuricemia, or gout; hence, further investigation is required.

Therefore, this study aimed to investigate the $\mathrm{XO}$ inhibitory and antihyperuricemic effects of CTLE and its constituent bioactive phytochemicals. Gas chromatographymass spectrometry (GC-MS) and high-performance liquid chromatography (HPLC) analyses were used to determine chemical profile. XO inhibitory and antihyperuricemic effects were evaluated by using a relevant in vivo mouse model of hyperuricemia and the in vitro enzymatic system.

\section{Materials and Methods}

2.1. Plant Materials. CT leaves were collected in Jeonnam Forest Resource Institute (Naju, South Korea) in May 2017 and identified by Dr. Deuk-Sil Oh affiliated to the Jeonnam Forest Resource Institute. A voucher specimen (MNUCSSCT-01) was stored in the Mokpo National University (Muan, South Korea). The leaves were processed as previously described [15]. Briefly, the air-dried, powdered CT leaves (100 g) were extracted twice with $1 \mathrm{~L}$ ethanol at approximately $20^{\circ} \mathrm{C}$ (room temperature) for $72 \mathrm{~h}$. The resultant ethanolic solution was filtered, evaporated, and freeze-dried to give CTLE.
2.2. Animals. Four-week-old male ICR mice were obtained from Orient Bio, Co. (Sungnam, South Korea). They were bred at $20-24^{\circ} \mathrm{C}$ (room temperature), with $12 \mathrm{~h}$ light (07:0019:00) and dark (19:00-07:00) cycles, and a relative humidity of $50 \% \pm 5 \%$ in a clean rodents' facility. The mice were housed in ventilated mice cages (Tecniplast USA, Inc.) with filtered and pathogen-free air. Water and laboratory mouse pellet food (Agribrands Purina Korea, Inc.) were provided ad libitum. All animal procedures were approved by the Institutional Animal Care and Use Committee (IACUC) of Jeonnam Bioindustry Foundation (approval number: JINR1503) and conducted in full compliance with the IACUC guidelines.

2.3. Chemical Profiling by GC-MS and HPLC Analyses. GCMS analysis was performed as reported previously with slight modifications [20]. An Agilent 7890 gas chromatograph system was coupled to a quadrupole Agilent 5975C electron ionization $(70 \mathrm{eV})$ mass spectrometric detector (Agilent Technologies, Palo Alto, CA, USA). The operational parameters for the GC-MS analysis are listed in Table 1. In addition, we purified and identified two constituents (rutin and kaempferol) by using preparative column liquid chromatography (prep-LC) and preparative thin layer chromatography. The analytical conditions for prep-LC are summarized in Table 1. Then, constituent profiling of CTLE was performed by using an Alliance 2695 HPLC system (Waters; Milford, MA, USA) coupled to a photodiode array detector at the wave length of $320 \mathrm{~nm}$. An Agilent Zorbax extended C18 analytical column $(150 \mathrm{~mm} \times 5 \mathrm{~mm} ; 5 \mu \mathrm{m})$ was used with a filtered and degassed mobile phase that consisted of solvents A (acetonitrile) and B ( $0.2 \%$ phosphoric acid). Gradient elution (from 10/90 to $100 / 0$, v/v) was performed at flow rate of $0.8 \mathrm{~mL} / \mathrm{min}$. The column temperature and sample injection volume were $25^{\circ} \mathrm{C}$ and $10 \mu \mathrm{L}$, respectively.

2.4. Determination of In Vitro Xanthine Oxidase (XO) Inhibitory Activity. XO inhibitory activity was determined through the measurement of uric acid formation in the $\mathrm{XO}$ enzyme assay system, as described previously [21]. The enzyme reaction mixture (total volume: $1000 \mu \mathrm{L}$ ) consisted of $100 \mu \mathrm{L} \mathrm{XO}(0.2 \mathrm{U} / \mathrm{mL}), 200 \mu \mathrm{L}$ xanthine $(1 \mathrm{mM}$ dissolved in $0.1 \mathrm{~N} \mathrm{NaOH}$ ), $100 \mu \mathrm{L}$ analysis sample or allopurinol (positive control), and $600 \mu \mathrm{L}$ phosphate buffer (100 mM; pH 7.4). The enzyme reaction was initiated through the addition of the enzyme and terminated through the addition of an aliquot of $1 \mathrm{~N} \mathrm{HCl}(0.2 \mathrm{~mL})$. The changes in the absorbance of the reaction mixture in comparison with the absorbance of blank were monitored at $290 \mathrm{~nm}$ for $15 \mathrm{~min}$ by using a UV/Vis spectrophotometer (PerkinElmer, Inc., Waltham, MA, USA). The $\mathrm{IC}_{50}$ of CTLE for the inhibition of in vitro XO activity was determined by nonlinear regression using GraphPad Prism 5.01 (GraphPad Software, San Diego, CA) according to the following equation:

$$
\mathrm{Y}=\min +\frac{\max -\min }{1+\left(\mathrm{X} / \mathrm{IC}_{50}\right)^{-\mathrm{P}}}
$$

where $\mathrm{X}$ and $\mathrm{Y}$ are the inhibitor (CTLE) concentration and response, respectively. Max and Min are the initial and final 
TABLE 1: Analytical conditions of the GC-MS and preparative HPLC methods.

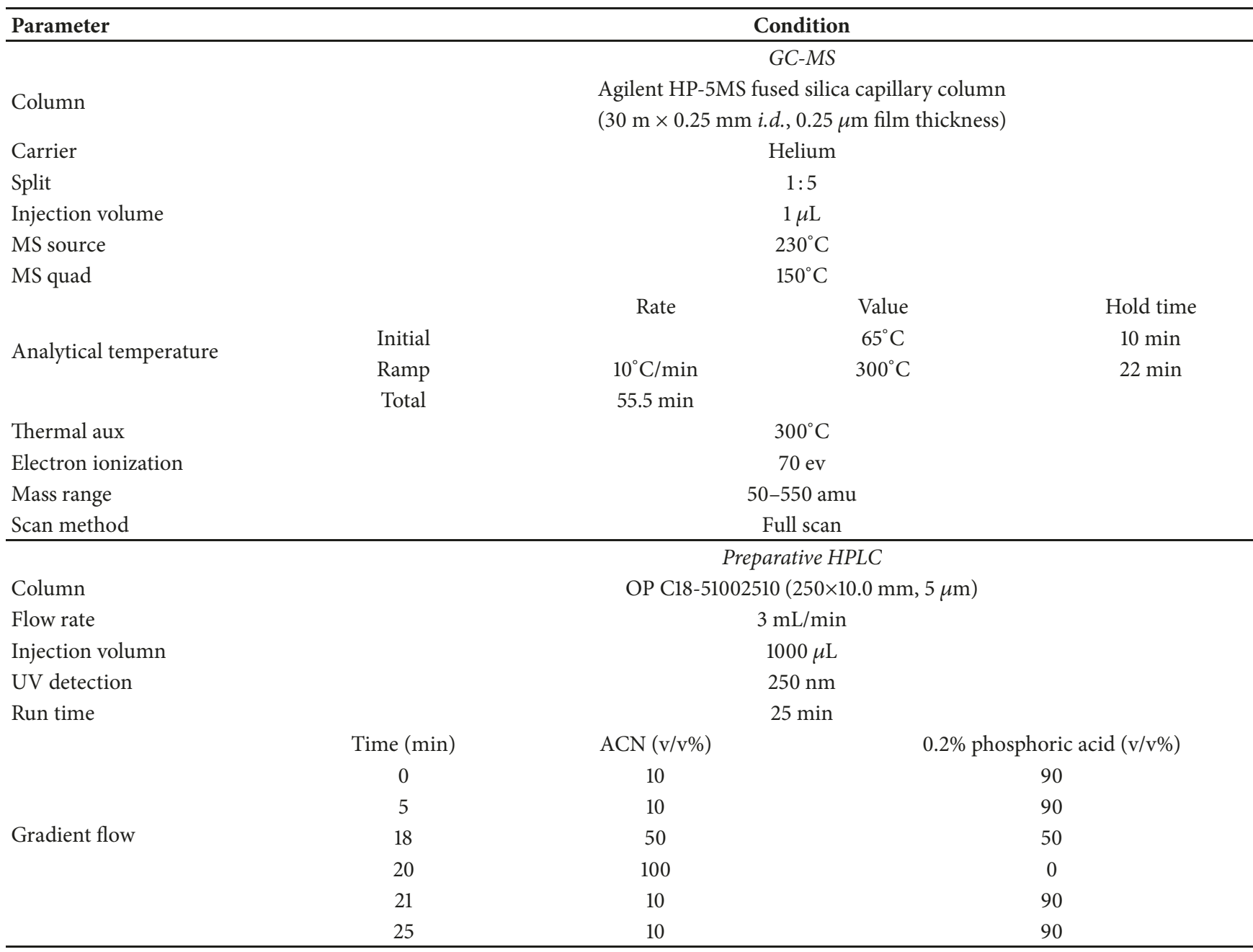

$\mathrm{Y}$ value, respectively, and the exponent $\mathrm{P}$ represents the Hill coefficient.

2.5. Pretreatment and Hyperuricemia Induction in Mice. CTLE or ALP was suspended in $0.3 \%$ carboxymethylcellulose (CMC) aqueous solution. The mice were divided into five groups ( $n=5$ for each group) and pretreated orally once per day for 7 days, as follows: the mice in two negative control groups received $0.3 \% \mathrm{CMC}$ aqueous solution (NOR and $\mathrm{HU}$ groups); the mice in the positive control group received ALP suspension at $10 \mathrm{mg} / \mathrm{kg}$ (ALP group); the mice in CTLE30 and CTLE100 groups received CTLE suspension at 30 and $100 \mathrm{mg} / \mathrm{kg}$, respectively. To induce hyperuricemia, all mice, except those in the NOR group, were intraperitoneally given potassium oxonate (uricase inhibitor; $250 \mathrm{mg} / \mathrm{kg}$ dissolved in PBS) $1 \mathrm{~h}$ prior to the final pretreatment on day 7 (mice in the NOR group received PBS instead of potassium oxonate) [22]. Finally, $1 \mathrm{~h}$ after the final pretreatment on day 7 , approximately $500 \mu \mathrm{L}$ blood was collected via the tail vein, allowed to clot at $4^{\circ} \mathrm{C}$ for $1 \mathrm{~h}$, and centrifuged at $10,000 \mathrm{~g}$ for $15 \mathrm{~min}$ to obtain serum. The resultant serum samples were stored at $-80^{\circ} \mathrm{C}$ for further analysis.
2.6. Determination of In Vivo Serum Uric Acid Concentration and XO Activity. Serum concentration of uric acid was determined by using a standard diagnostic kit (Abcam; Cambridge, UK). The activity of XO in mouse liver and serum (expressed as micromoles of uric acid formed per minute (U) per milligram protein) was spectrophotometrically determined through the measurement of formation of uric acid from xanthine (in triplicate) [23]. Briefly, mouse liver (0.5 g) was homogenized in $1 \mathrm{~mL}$ sodium phosphate buffer $(50 \mathrm{mM}$; $\mathrm{pH}$ 7.4). The homogenate was centrifuged at $3,000 \mathrm{~g}$ for 10 min at $4^{\circ} \mathrm{C}$. After removal of the lipid layer, the supernatant was centrifuged at $10,000 \mathrm{~g}$ for $60 \mathrm{~min}$ at $4^{\circ} \mathrm{C}$. The resultant supernatant was used as the analysis sample for the analysis of $\mathrm{XO}$ residual activity and total protein concentration. To measure XO activity, $10 \mu \mathrm{L}$ of sample was transferred into a test tube containing $540 \mu \mathrm{L}$ of $1 \mathrm{mM}$ potassium oxonate solution dissolved in sodium phosphate buffer $(50 \mathrm{mM} ; \mathrm{pH}$ 7.4) and incubated at $35^{\circ} \mathrm{C}$ for $15 \mathrm{~min}$. Then, the reaction was initiated through the addition of $120 \mu \mathrm{L}$ of xanthine solution (250 $\mathrm{mM})$. After 0 and $30 \mathrm{~min}$, the reaction was stopped through the addition of $100 \mu \mathrm{L}$ of $\mathrm{HCl}(600 \mathrm{mM})$, and the test tube was centrifuged at $3,000 \mathrm{~g}$ for $5 \mathrm{~min}$. The absorbance of the supernatant was measured at $295 \mathrm{~nm}$ by using the 


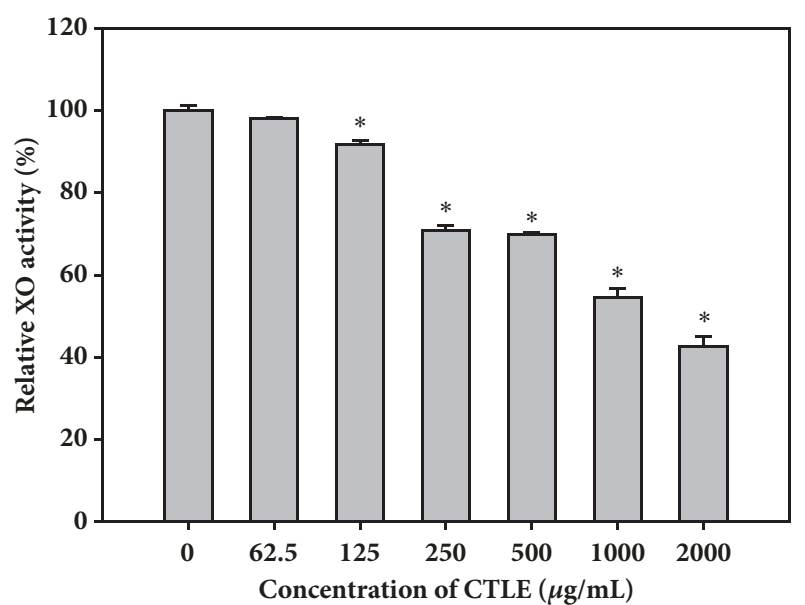

FIgURE 1: In vitro xanthine oxidase (XO) inhibitory activity of CTLE at concentrations between 0 and $2000 \mu \mathrm{g} / \mathrm{mL}$. The rectangular bars and their error bars represent the means and standard deviations, respectively $(n=5)$. The asterisks indicate values that are significantly different from those of the control $(0 \mu \mathrm{g} / \mathrm{mL})$ group $(p<0.05)$.

UV/Vis spectrophotometer. The total protein concentration of the sample was measured by using the Bradford method [20].

2.7. Statistical Analysis. To analyze the differences between two means of unpaired data, Student's $t$-test was performed. To analyze the differences among three or more means of unpaired data, analysis of variance (post hoc test: Tukey's HSD test) was performed. A $p$-value less than 0.05 was considered to be statistically significant. All data were expressed as the mean \pm standard deviation and rounded to three significant figures.

\section{Results}

3.1. In Vitro XO Inhibitory Effect of CTLE. Figure 1 shows the XO inhibitory effect of CTLE at various concentrations. CTLE at $125 \mu \mathrm{g} / \mathrm{mL}$ or higher significantly inhibited the in vitro XO activity, whereas CTLE at $62.5 \mu \mathrm{g} / \mathrm{mL}$ did not. CTLE inhibited $\mathrm{XO}$ activity in a concentration-dependent manner. The $\mathrm{IC}_{50}$ of CTLE for the inhibition of XO activity was estimated to be $368.2 \mu \mathrm{g} / \mathrm{mL}$.

3.2. Effect of CTLE on In Vivo Serum Uric Acid Levels. Figure 2 shows the effect of CTLE on the serum concentrations of uric acid in hyperuricemic mice. At $1 \mathrm{~h}$ after intraperitoneal injection of potassium oxonate, the serum uric acid concentrations in the hyperuricemic control mice group were significantly higher than those in the normal control mice group, by approximately 2 -fold $(7.9 \pm 1.4 \mathrm{nM}$ versus $4.0 \pm 1.0 \mathrm{nM}$ ), which indicated that the mouse model of hyperuricemia was successfully established, as reported previously [22]. The serum uric acid concentrations in the normal control mice group were comparable to those in the hyperuricemic mice groups that were pretreated with allopurinol or CTLE at doses of 30 and $100 \mathrm{mg} / \mathrm{kg}$ for 1

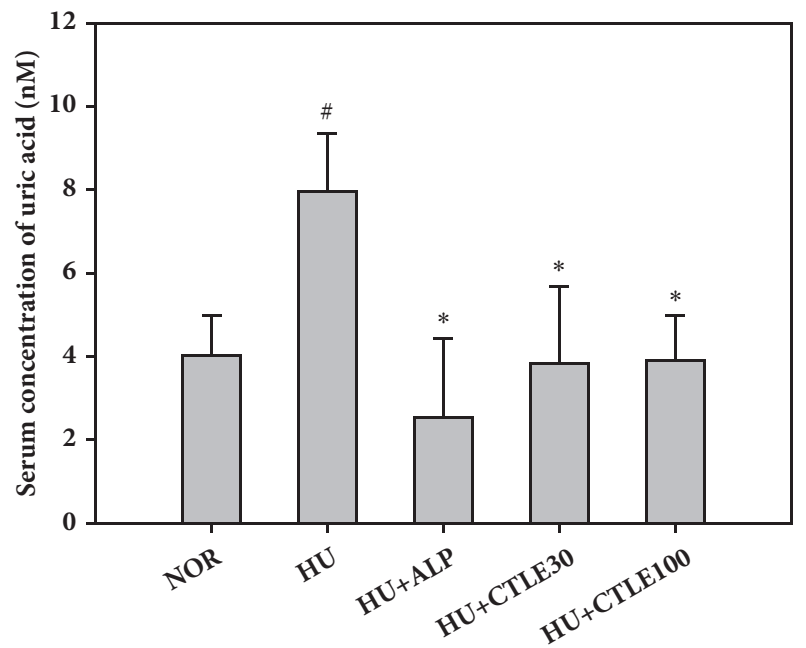

FIGURE 2: Serum uric acid levels after the oral administration of saline in normal mice (NOR) and after the oral administration of saline (HU), allopurinol at a dose of $10 \mathrm{mg} / \mathrm{kg}(\mathrm{HU}+\mathrm{ALP})$, or CTLE at doses of $30 \mathrm{mg} / \mathrm{kg}$ (HU+CTLE30) and $100 \mathrm{mg} / \mathrm{kg}$ (HU+CTLE100) for 7 days prior to the induction of hyperuricemia in mice. The rectangular bars and their error bars represent the means and standard deviations, respectively $(n=5)$. The asterisks and pound sign indicate values that are significantly different from those of the HU and NOR group, respectively $(p<0.05)$.

week prior to the induction of hyperuricemia. The serum uric acid levels in allopurinol-pretreated (HU+ALP) and CTLEpretreated hyperuricemic mice groups (HU+CTLE30 and $\mathrm{HU}+\mathrm{CTLE100)}$ were $2.5 \pm 1.9 \mathrm{nM}, 3.8 \pm 1.9 \mathrm{nM}$, and $3.9 \pm$ $1.1 \mathrm{nM}$, respectively.

3.3. Effect of CTLE on In Vivo Hepatic and Serum XO Activity. The effects of CTLE on hepatic and serum XO activity in hyperuricemic mice are shown in Figure 3. There was no significant difference in hepatic or serum XO activity between the normal and hyperuricemic control mice groups. However, hepatic XO activity in hyperuricemic mice was significantly reduced by the 1 -week oral pretreatment of allopurinol (by $48.8 \%$ ) or 30 and $100 \mathrm{mg} / \mathrm{kg}$ CTLE (by 39.1 and $41.8 \%$, respectively), as shown in Figure 3(a). Similarly, serum $\mathrm{XO}$ activity in hyperuricemic mice was significantly reduced by the 1-week oral pretreatment of allopurinol (by $57.7 \%$ ) or 30 and $100 \mathrm{mg} / \mathrm{kg}$ CTLE (by 30.7 and $50.1 \%$, respectively), as shown in Figure 3(b).

3.4. Chemical Profiling by GC-MS and HPLC Analyses. GC-MS and HPLC analyses were performed to identify bioactive phytochemicals from CTLE. Representative GCMS and HPLC chromatograms of phytochemicals with their retention times are shown in Figures 4 and 5, respectively. The contents of the phytochemicals identified by GC-MS and HPLC analyses are listed in Table 2. Linolenic acid, vitamin $\mathrm{E}$, hexadecanoic acid, $\beta$-sitosterol, and stigmasterol were identified by GC-MS analysis, whereas rutin and kaempferol were identified by HPLC analysis. 


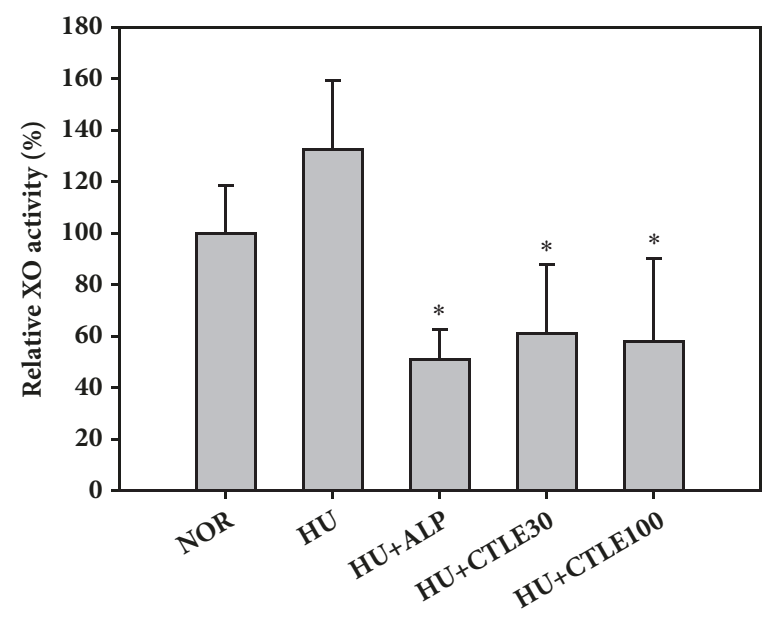

(a)

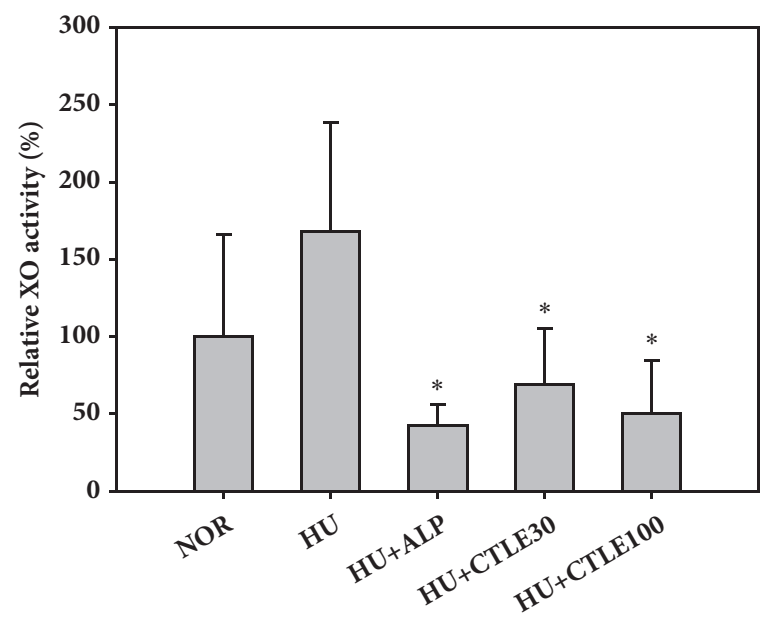

(b)

FIGURE 3: Relative activity of hepatic (a) and serum (b) xanthine oxidase (XO) after the oral administration of saline in normal mice (NOR) and after the oral administration of saline (HU), allopurinol at a dose of $10 \mathrm{mg} / \mathrm{kg}$ (HU+ALP), or CTLE at doses of 30 mg/kg (HU+CTLE30) and $100 \mathrm{mg} / \mathrm{kg}$ (HU+CTLE100) in hyperuricemic mice for 7 days. The rectangular bars and their error bars represent the means and standard deviations, respectively $(n=5)$. The asterisks indicate values that are significantly different from those of the HU group $(p<0.05)$.

TABLE 2: The main phytochemicals identified from CTLE.

\begin{tabular}{lcc}
\hline Constituent & Content (\%) \\
\hline & $G C-M S$ & \\
Linolenic acid & & 6.92 \\
Vitamin E & 5.62 \\
Hexadecanoic acid & 4.56 \\
$\beta$-sitosterol & & 2.93 \\
Stigmasterol & HPLC & 0.6 \\
& & \\
Rutin & 0.44 \\
Kaempferol & & 0.27 \\
\hline
\end{tabular}

\subsection{In Vitro XO Inhibitory Effects of Phytochemicals Identified} by HPLC Analysis. The concentration dependent in vitro $\mathrm{XO}$ inhibitory activity of the two flavonoids identified by HPLC analysis is shown in Figure 6. Compared with rutin, kaempferol showed notably higher levels of XO inhibitory activity within the concentration range of the compounds tested.

\section{Discussion}

This study has provided novel experimental data on the antihyperuricemic effects of CTLE and its constituent active phytochemicals. In our previous study, the conditions for the ethanolic extraction of CT leaf were evaluated to provide optimum biological activity and chemical profile [15]. As a result, CT leaf extract prepared with $100 \%$ ethanol exhibited the highest total flavonoid content and $\mathrm{XO}$ inhibitory activity [15]. XO inhibitory activity in several plant extracts has been attributed to the presence of flavonoids [24]. Thus, the $100 \%$ ethanolic extract (CTLE) was selected and further evaluated for antihyperuricemic potential in the present study.
As shown in Figures 2 and 3, CTLE at doses of 30 and 100 $\mathrm{mg} / \mathrm{kg}$ significantly reduced serum uric acid levels and inhibited hepatic and serum XO activities in hyperuricemic mice. These results clearly showed that the 1-week pretreatment with oral CTLE significantly alleviated the hyperuricemic state in mice. Meanwhile, the average values of hepatic and serum XO activity were slightly higher in the hyperuricemic control mice group than in the normal mice group, but the differences were not statistically significant $(p=0.38$ for hepatic XO activity and 0.33 for serum XO activity). This suggested that the intraperitoneal administration of potassium oxonate, an uricase inhibitor, did not significantly modulate the $\mathrm{XO}$ activity in mice.

As shown in Table 2, several bioactive constituents related to XO-inhibitory, antihyperuricemic, and/or anti-gout properties were identified from CTLE by GC-MS and HPLC analyses. Ferraz-Filha et al. (2016) reported that stigmasterol reduced serum uric acid levels through the inhibition of hepatic XO activity in hyperuricemic mice. It was also reported that stigmasterol and $\beta$-sitosterol alleviated the local paw edema induced by monosodium urate crystals in mice $[25,26]$. Mohd Fahami et al. (2012) reported that vitamin E, a well-known antioxidant, exhibited gastroprotective effects through the reduction in gastric XO activity in rats. There have been no previous studies related to the effects of linolenic acid and hexadecanoic acid on XO activity, hyperuricemia, and/or gout. However, it is well known that these two phytochemicals have anti-inflammatory activity and are able to potentially modulate secondary inflammatory damage in gouty arthritis, which warrant further investigation [27, 28]. Additionally, we identified two different $\mathrm{XO}$ inhibitory flavonoids, i.e., kaempferol and rutin, from CTLE. Kaempferol is a major flavonoid present widely in the diet and Chinese herbal medicines; it comprises $22 \%$ $29 \%$ of the total flavonoid intake [29]. Our present results showed that kaempferol could serve as a potential $\mathrm{XO}$ 


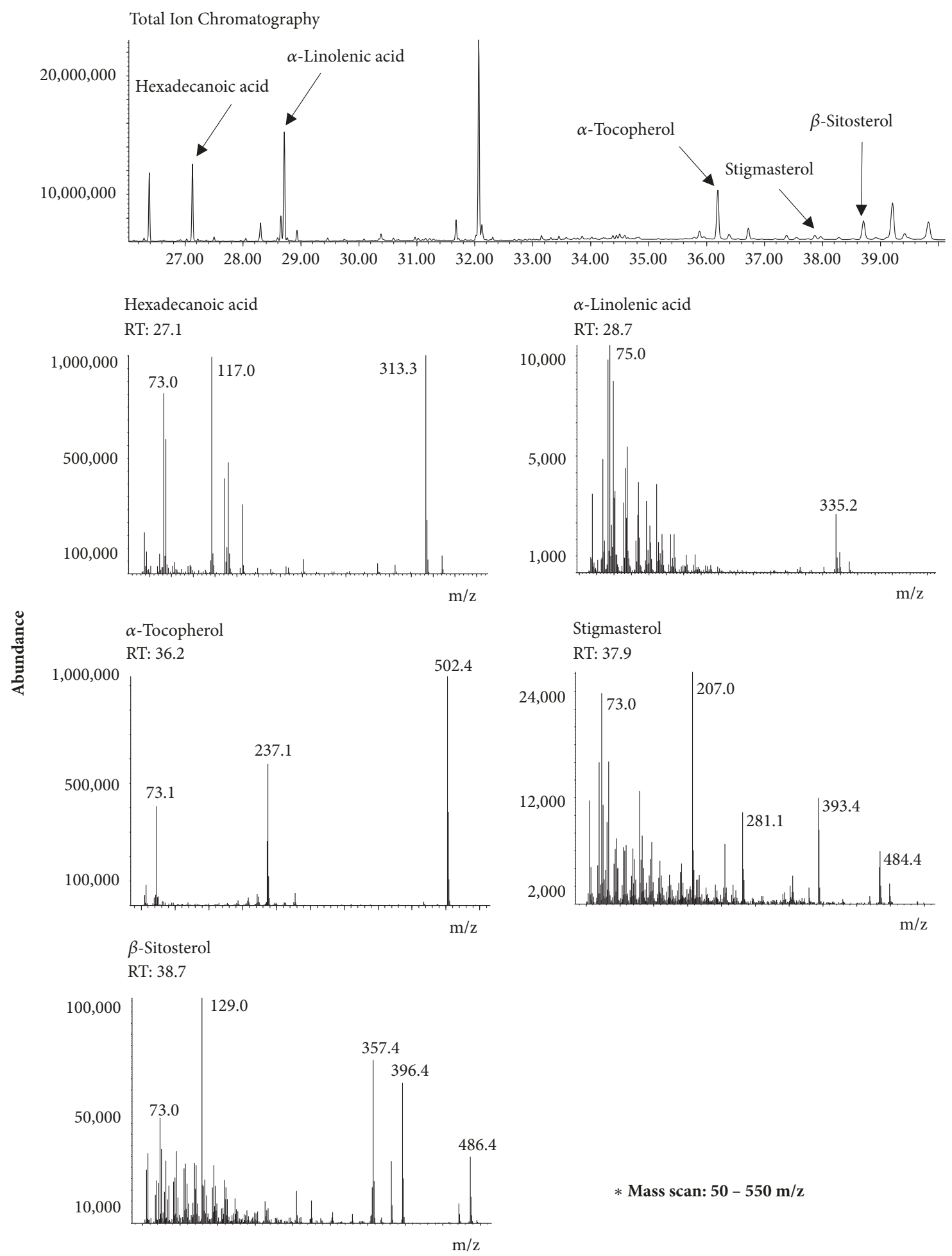

FIGURE 4: Representative GC-MS chromatogram of CTLE.

inhibitor, which was consistent with previous reports [30, 31]. Moreover, kaempferol was demonstrated to inhibit $\mathrm{XO}$ activity in a competitive manner through the insertion at the hydrophobic active site of XO to interrupt the entrance of substrate [30]. Previous studies also reported that rutin reduced serum uric acid levels, serum XO activity, and hepatic XO activity in hyperuricemic mice $[32,33]$. However, compared with kaempferol, rutin exerted relatively lower in vitro XO inhibitory activity (Figure 6).

The effective dose levels found in this study (30 and 100 $\mathrm{mg} / \mathrm{kg}$ ) appear to be relatively lower than those reported in previous studies on plant extracts with antihyperuricemic 


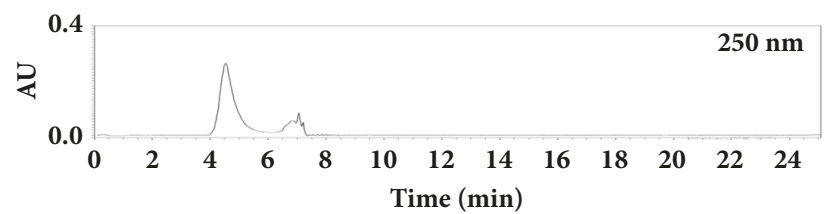

(a)

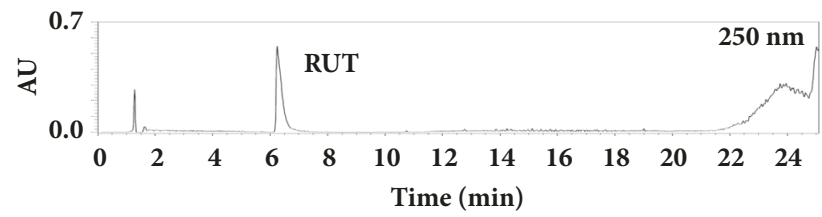

(b)

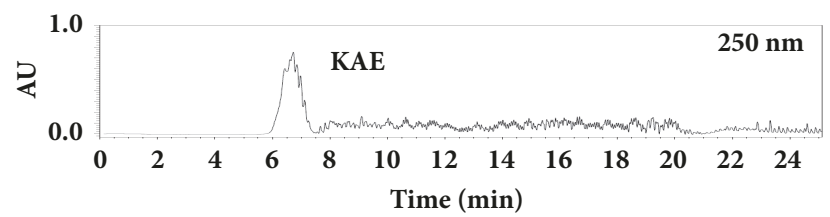

(c)

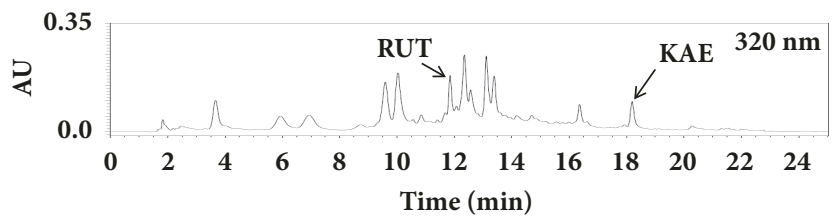

(d)

Figure 5: Representative chromatographic profiles showing the bioactive constituents of CTLE. (a) Elution profile of CTLE using prep-LC; (b) elution profile of purified rutin (RUT) using prep-LC; (c) elution profile of purified kaempferol (KAE) using prep-LC; (d) HPLC chromatogram of CTLE.

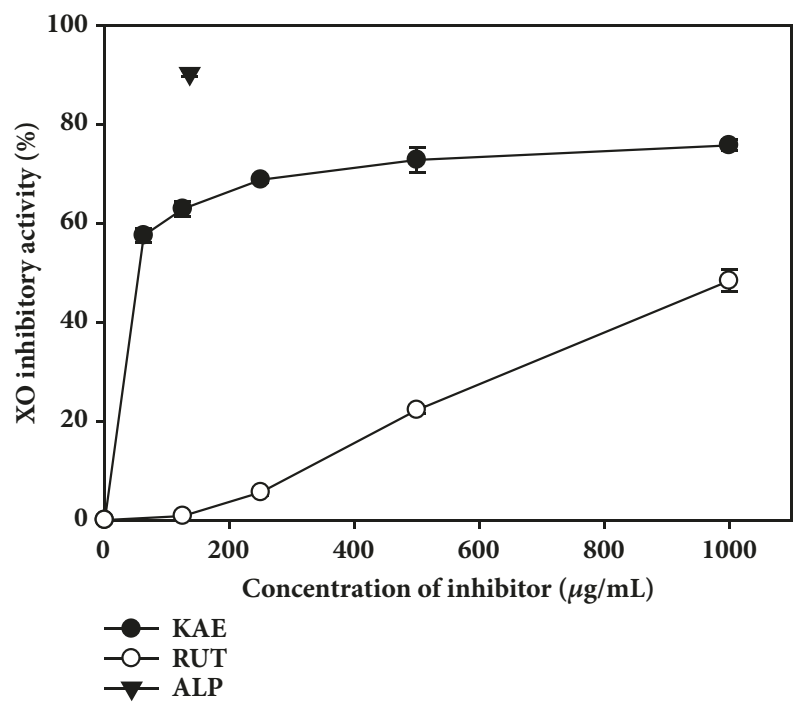

FIgURE 6: Xanthine oxidase (XO) inhibitory activity of allopurinol (ALP) and bioactive phytochemicals identified from CTLE (kaempferol, KAE; rutin, RUT). The bullet symbols and their error bars represent the means and standard deviations, respectively $(n=$ 5). ALP was tested at a concentration of $136 \mu \mathrm{g} / \mathrm{mL}$, and KAE and RUT were tested at concentrations between 0 and $1000 \mu \mathrm{g} / \mathrm{mL}$. activity (100-978 mg/kg) [34-37]. The daily mouse doses of 30 and $100 \mathrm{mg} / \mathrm{kg}$ can be converted into human equivalent doses of 146 and $487 \mathrm{mg} / 60 \mathrm{~kg}$ human/day, based on a conversion factor of 12.33 [38]. As the process yield for the preparation of CTLE was $16.9 \%$, approximately $1-3 \mathrm{~g}$ of raw plant materials would be required for the preparation of each CTLE dose in a clinical study. These are feasible and advantageous circumstances for the industrial development of dietary or medicinal formulations containing CTLE.

\section{Conclusions}

This study demonstrated that relatively low dose of CTLE (30 and $100 \mathrm{mg} / \mathrm{kg}$ ) significantly alleviated hyperuricemia through the reduction of serum and hepatic XO activity. Moreover, CTLE was found to contain several XO inhibitory and/or antihyperuricemic phytochemicals such as stigmasterol, $\beta$-sitosterol, vitamin $\mathrm{E}$, rutin, and kaempferol. To the best of our knowledge, this is the first report on the $\mathrm{XO}$ inhibitory and antihyperuricemic effects of CTLE and its active phytochemicals. Our present results have shown that CTLE may offer a promising alternative to allopurinol for the treatment of hyperuricemia and gout.

\section{Data Availability}

No data were used to support this study.

\section{Conflicts of Interest}

The authors have declared that there are no conflicts of interest.

\section{Authors' Contributions}

Seung-Hui Song and Dae-Hun Park contributed equally to this work.

\section{Acknowledgments}

This work was supported by the National Research Foundation of Korea (NRF) grant funded by the Korean government (MSIP; Ministry of Science, ICT \& Future Planning) (No. NRF-2017R1C1B5015187) and by the Korea Institute of Planning and Evaluation for Technology in Food, Agriculture, Forestry and Fisheries (IPET) through the Agri-Bioindustry Technology Development Program, funded by Ministry of Agriculture, Food and Rural Affairs (MAFRA; 316007-5).

\section{References}

[1] P. Richette and T. Bardin, "Gout," The Lancet, vol. 375, no. 9711, pp. 318-328, 2010.

[2] M. D. Harris, L. B. Siegel, and J. A. Alloway, "Gout and hyperuricemia," American Family Physician, vol. 59, no. 4, pp. 925-934, 1999.

[3] C.-F. Kuo, M. J. Grainge, W. Zhang, and M. Doherty, "Global epidemiology of gout: prevalence, incidence and risk factors," Nature Reviews Rheumatology, vol. 11, no. 11, pp. 649-662, 2015. 
[4] H. M. Kramer and G. Curhan, "The association between gout and nephrolithiasis: the national health and nutrition examination survey III, 1988-1994," American Journal of Kidney Diseases, vol. 40, no. 1, pp. 37-42, 2002.

[5] Rui Liu, Cheng Han, Di Wu et al., "Prevalence of Hyperuricemia and Gout in Mainland China from 2000 to 2014: A Systematic Review and Meta-Analysis," BioMed Research International, vol. 2015, Article ID 762820, 12 pages, 2015.

[6] Q. Li, X. Li, J. S. Kwong et al., "Diagnosis and treatment for hyperuricaemia and gout: a protocol for a systematic review of clinical practice guidelines and consensus statements," $B M J$ Open, vol. 7, no. 6, p. e014928, 2017.

[7] Y. Taniguchi, T. Hayashi, K. Tsumura, G. Endo, S. Fujii, and K. Okada, "Serum uric acid and the risk for hypertension and type 2 diabetes in Japanese men: The Osaka health survey," Journal of Hypertension, vol. 19, no. 7, pp. 1209-1215, 2001.

[8] F. Nyberg, L. Horne, R. Morlock et al., "Comorbidity Burden in Trial-Aligned Patients with Established Gout in Germany, UK, US, and France: a Retrospective Analysis," Advances in Therapy, vol. 33, no. 7, pp. 1180-1198, 2016.

[9] L. E. Clarson, S. L. Hider, J. Belcher, C. Heneghan, E. Roddy, and C. D. Mallen, "Increased risk of vascular disease associated with gout: A retrospective, matched cohort study in the UK Clinical Practice Research Datalink," Annals of the Rheumatic Diseases, vol. 74, no. 4, pp. 642-647, 2015.

[10] L. Li, M. Teng, Y. Liu et al., "Anti-Gouty Arthritis and Antihyperuricemia Effects of Sunflower (Helianthus annuus) Head Extract in Gouty and Hyperuricemia Animal Models," BioMed Research International, vol. 2017, Article ID 5852076, 9 pages, 2017.

[11] L. K. Stamp, J. L. O’Donnell, M. Zhang et al., "Using allopurinol above the dose based on creatinine clearance is effective and safe in patients with chronic gout, including those with renal impairment," Arthritis \& Rheumatology, vol. 63, no. 2, pp. 412421, 2011.

[12] I.-S. Yoon, D.-H. Park, S.-H. Ki, and S.-S. Cho, "Effects of extracts from Corylopsis coreana Uyeki (Hamamelidaceae) flos on xanthine oxidase activity and hyperuricemia," Journal of Pharmacy and Pharmacology, vol. 68, no. 12, pp. 1597-1603, 2016.

[13] M. Gliozzi, N. Malara, S. Muscoli, and V. Mollace, "The treatment of hyperuricemia," International Journal of Cardiology, vol. 213, pp. 23-27, 2016.

[14] S. H. Chang, E. J. Jung, D. G. Lim et al., "Anti-inflammatory action of Cudrania tricuspidata on spleen cell and Tlymphocyte proliferation," Journal of Pharmacy and Pharmacology, vol. 60, no. 9, pp. 1221-1226, 2008.

[15] S. Song, S. Ki, D. Park et al., "Quantitative Analysis, Extraction Optimization, and Biological Evaluation of Cudrania tricuspidata Leaf and Fruit Extracts," Molecules, vol. 22, no. 9, p. 1489, 2017.

[16] G.-S. Jeong, D.-S. Lee, and Y.-C. Kim, "Cudratricusxanthone A from Cudrania tricuspidata suppresses pro-inflammatory mediators through expression of anti-inflammatory heme oxygenase-1 in RAW264.7 macrophages," International Immunopharmacology, vol. 9, no. 2, pp. 241-246, 2009.

[17] Y.-H. Tian, H.-C. Kim, J.-M. Cui, and Y.-C. Kim, "Hepatoprotective constituents of Cudrania tricuspidata," Archives of Pharmacal Research, vol. 28, no. 1, pp. 44-48, 2005.

[18] B. W. Lee, J. H. Lee, S.-T. Lee et al., "Antioxidant and cytotoxic activities of xanthones from Cudrania tricuspidata," Bioorganic
\& Medicinal Chemistry Letters, vol. 15, no. 24, pp. 5548-5552, 2005.

[19] Y. H. Jo, K.-M. Choi, Q. Liu et al., "Anti-obesity effect of 6,8-diprenylgenistein, an isoflavonoid of Cudrania tricuspidata fruits in high-fat diet-induced obese mice," Nutrients, vol. 7, no. 12, pp. 10480-10490, 2015.

[20] I.-S. Yoon, D.-H. Park, J.-E. Kim et al., "Identification of the biologically active constituents of Camellia japonica leaf and anti-hyperuricemic effect in vitro and in vivo," International Journal of Molecular Medicine, vol. 39, no. 6, pp. 1613-1620, 2017.

[21] R. Arimboor, M. Rangan, S. G. Aravind, and C. Arumughan, "Tetrahydroamentoflavone (THA) from Semecarpus anacardium as a potent inhibitor of xanthine oxidase," Journal of Ethnopharmacology, vol. 133, no. 3, pp. 1117-1120, 2011.

[22] L.-N. Huo, W. Wang, C.-Y. Zhang et al., "Bioassay-guided isolation and identification of xanthine oxidase inhibitory constituents from the leaves of perilla frutescens," Molecules, vol. 20, no. 10, pp. 17848-17859, 2015.

[23] R. D. C. Lemos Lima, F. C. Ferrari, M. R. De Souza, B. M. De Sá Pereira, C. A. De Paula, and D. A. Saúde-Guimarães, "Effects of extracts of leaves from Sparattosperma leucanthum on hyperuricemia and gouty arthritis," Journal of Ethnopharmacology, vol. 161, pp. 194-199, 2015.

[24] X. Ling and W. Bochu, "A review of phytotherapy of gout: perspective of new pharmacological treatments," Die Pharmazie, vol. 69, no. 4, pp. 243-256, 2014.

[25] Z. S. Ferraz-Filha, M. C. D. P. Michel Araújo, F. C. Ferrari, I. P. A. R. Dutra, and D. A. Saúde-Guimarães, "Tabebuia roseoalba: In Vivo Hypouricemic and Anti-inflammatory Effects of Its Ethanolic Extract and Constituents," Planta Medica, vol. 82, no. 16, pp. 1395-1402, 2016.

[26] M. R. De Souza, C. A. De Paula, M. L. Pereira De Resende, A. Grabe-Guimarães, J. D. De Souza Filho, and D. A. SaúdeGuimarães, "Pharmacological basis for use of Lychnophora trichocarpha in gouty arthritis: Anti-hyperuricemic and antiinflammatory effects of its extract, fraction and constituents," Journal of Ethnopharmacology, vol. 142, no. 3, pp. 845-850, 2012.

[27] S. Y. Park, R. Seetharaman, M. J. Ko et al., "Ethyl linoleate from garlic attenuates lipopolysaccharide-induced pro-inflammatory cytokine production by inducing heme oxygenase- 1 in RAW264.7 cells," International Immunopharmacology, vol. 19, no. 2, pp. 253-261, 2014.

[28] V. Aparna, K. V. Dileep, P. K. Mandal, P. Karthe, C. Sadasivan, and M. Haridas, "Anti-inflammatory property of nhexadecanoic acid: structural evidence and kinetic assessment," Chemical Biology \& Drug Design, vol. 80, no. 3, pp. 434-439, 2012.

[29] P. Niering, G. Michels, W. Wätjen et al., "Protective and detrimental effects of kaempferol in rat H4IIE cells: Implication of oxidative stress and apoptosis," Toxicology and Applied Pharmacology, vol. 209, no. 2, pp. 114-122, 2005.

[30] Y. Wang, G. Zhang, J. Pan, and D. Gong, "Novel insights into the inhibitory mechanism of kaempferol on xanthine oxidase," Journal of Agricultural and Food Chemistry, vol. 63, no. 2, pp. 526-534, 2015.

[31] A. Nagao, M. Seki, and H. Kobayashi, "Inhibition of xanthine oxidase by flavonoids," Bioscience, Biotechnology, and Biochemistry, vol. 63, no. 10, pp. 1787-1790, 1999.

[32] J. Huang, S. Wang, M. Zhu, J. Chen, and X. Zhu, "Effects of genistein, apigenin, quercetin, rutin and astilbin on serum uric acid levels and xanthine oxidase activities in normal and 
hyperuricemic mice," Food and Chemical Toxicology, vol. 49, no. 9, pp. 1943-1947, 2011.

[33] J. X. Zhu, Y. Wang, L. D. Kong, C. Yang, and X. Zhang, "Effects of Biota orientalis extract and its flavonoid constituents, quercetin and rutin on serum uric acid levels in oxonate-induced mice and xanthine dehydrogenase and xanthine oxidase activities in mouse liver," Journal of Ethnopharmacology, vol. 93, no. 1, pp. 133-140, 2004.

[34] X. Wang, C.-P. Wang, Q.-H. Hu et al., "The dual actions of Sanmiao wan as a hypouricemic agent: down-regulation of hepatic XOD and renal mURAT1 in hyperuricemic mice," Journal of Ethnopharmacology, vol. 128, no. 1, pp. 107-115, 2010.

[35] S. Y. Wang, C. W. Yang, J. W. Liao, W. W. Zhen, F. H. Chu, and S. T. Chang, "Essential oil from leaves of Cinnamomum osmophloeum acts as a xanthine oxidase inhibitor and reduces the serum uric acid levels in oxonate-induced mice," Phytomedicine, vol. 15, no. 11, pp. 940-945, 2008.

[36] M. Umamaheswari, K. AsokKumar, A. Somasundaram, T. Sivashanmugam, V. Subhadradevi, and T. K. Ravi, "Xanthine oxidase inhibitory activity of some Indian medical plants," Journal of Ethnopharmacology, vol. 109, no. 3, pp. 547-551, 2007.

[37] X. Zhao, J. X. Zhu, S. F. Mo, Y. Pan, and L. D. Kong, "Effects of cassia oil on serum and hepatic uric acid levels in oxonateinduced mice and xanthine dehydrogenase and xanthine oxidase activities in mouse liver," Journal of Ethnopharmacology, vol. 103, no. 3, pp. 357-365, 2006.

[38] J. W. Shin, I. C. Seol, and C. G. Son, "Interpretation of animal dose and human equivalent dose for drug development," The Journal of Korean Oriental Medicine, vol. 31, no. 3, pp. 1-7, 2010. 


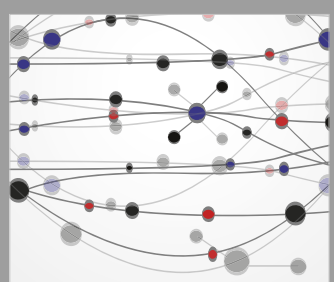

The Scientific World Journal
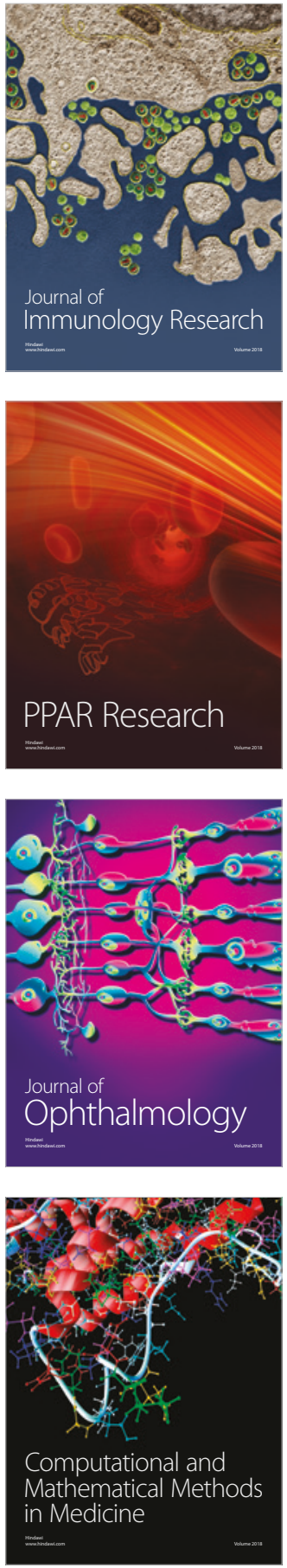

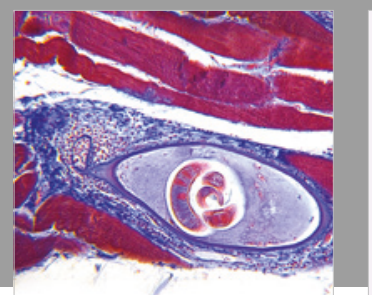

Gastroenterology Research and Practice

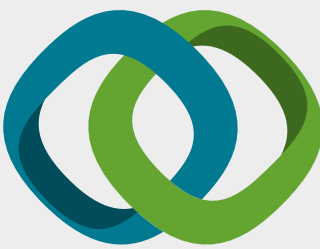

\section{Hindawi}

Submit your manuscripts at

www.hindawi.com
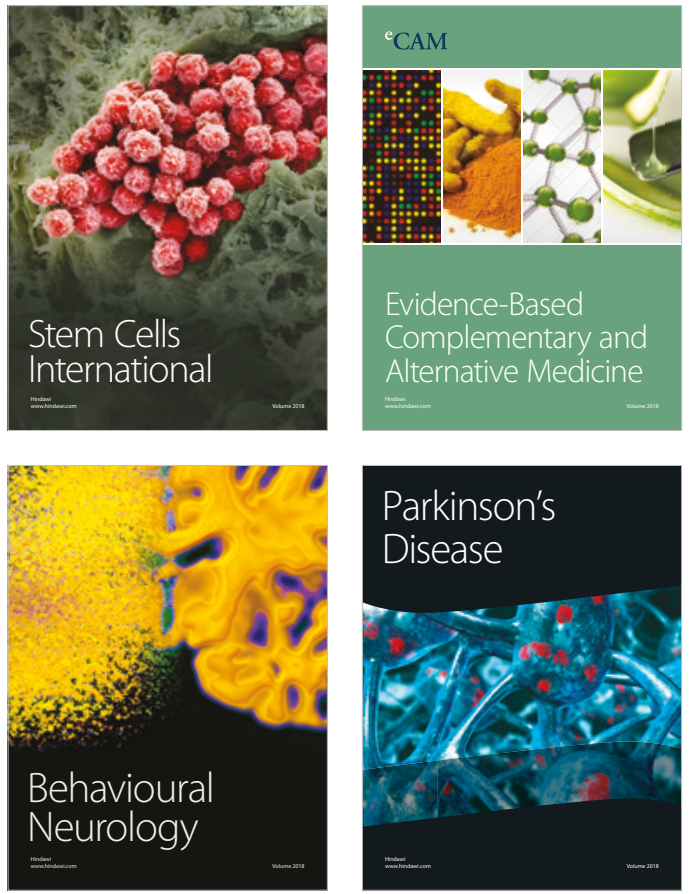

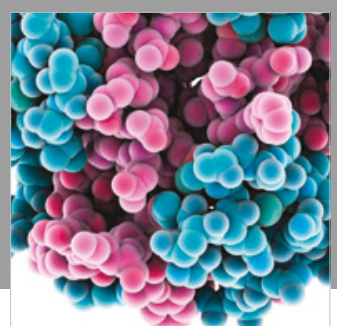

ournal of

Diabetes Research

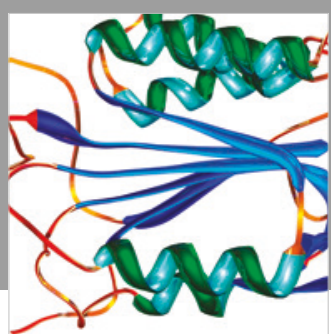

Disease Markers
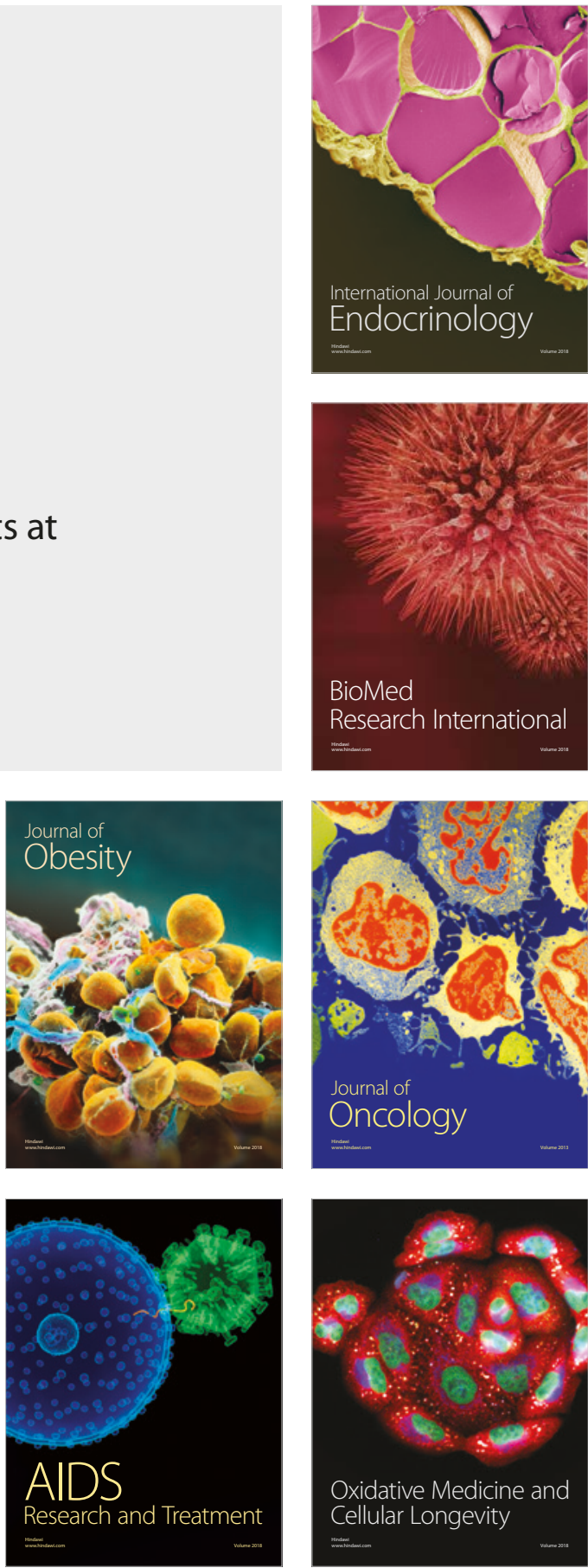